\title{
Endoscopic ultrasonography-guided hybrid rendezvous technique for pancreatic stenting in a patient with pancreatoduodenectomy
}

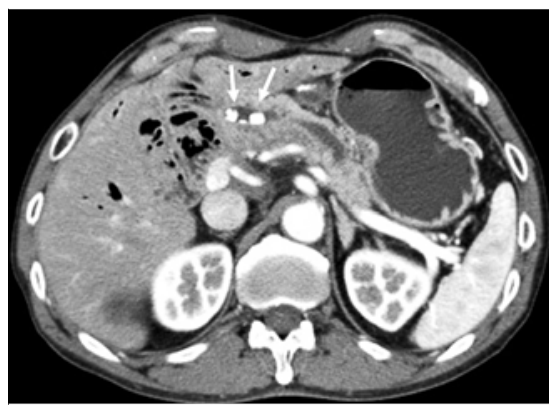

Fig. 1 Computed tomography imaging showing obstruction of the pancreaticojejunal anastomosis with pancreatic stones (arrows).

The endoscopic ultrasonography (EUS)guided rendezvous technique is used in patients who previously underwent a pancreatoduodenectomy. This procedure facilitates recognition of the orifice of the pancreatic duct $(\mathrm{PD})$, allows for cannulation of the obstructed PD $[1,2]$, and can be reattempted if the guidewire is dropped. The EUS-guided hybrid rendezvous technique is reported as an advanced technique for biliary drainage [3]. Here, we report that the technique was useful for PD drainage.

A 78-year-old man with recurring pancreatitis who had undergone a pancreaticoduodenectomy for biliary cancer 17 years previously was referred to our hospital. Computed tomography imaging showed obstruction of the PD with pancreatic stones ( $\triangleright$ Fig. 1 ). Balloon enteroscopy was attempted to drain the PD; however, the orifice of the PD was not recognizable. EUS-guided treatment for the obstruction was then performed ( Fig.2), and the PD was punctured transgastrically using a 19-gauge needle (EZ shot 3 Plus; Olympus Medical, Tokyo, Japan). A 0.025-inch guidewire with a cannulation catheter (PR-110Q; Olympus Medical) was advanced through the pancreaticojejunal anastomosis. The echoendoscope was switched to an enteroscope. The guidewire was brought into the ac-
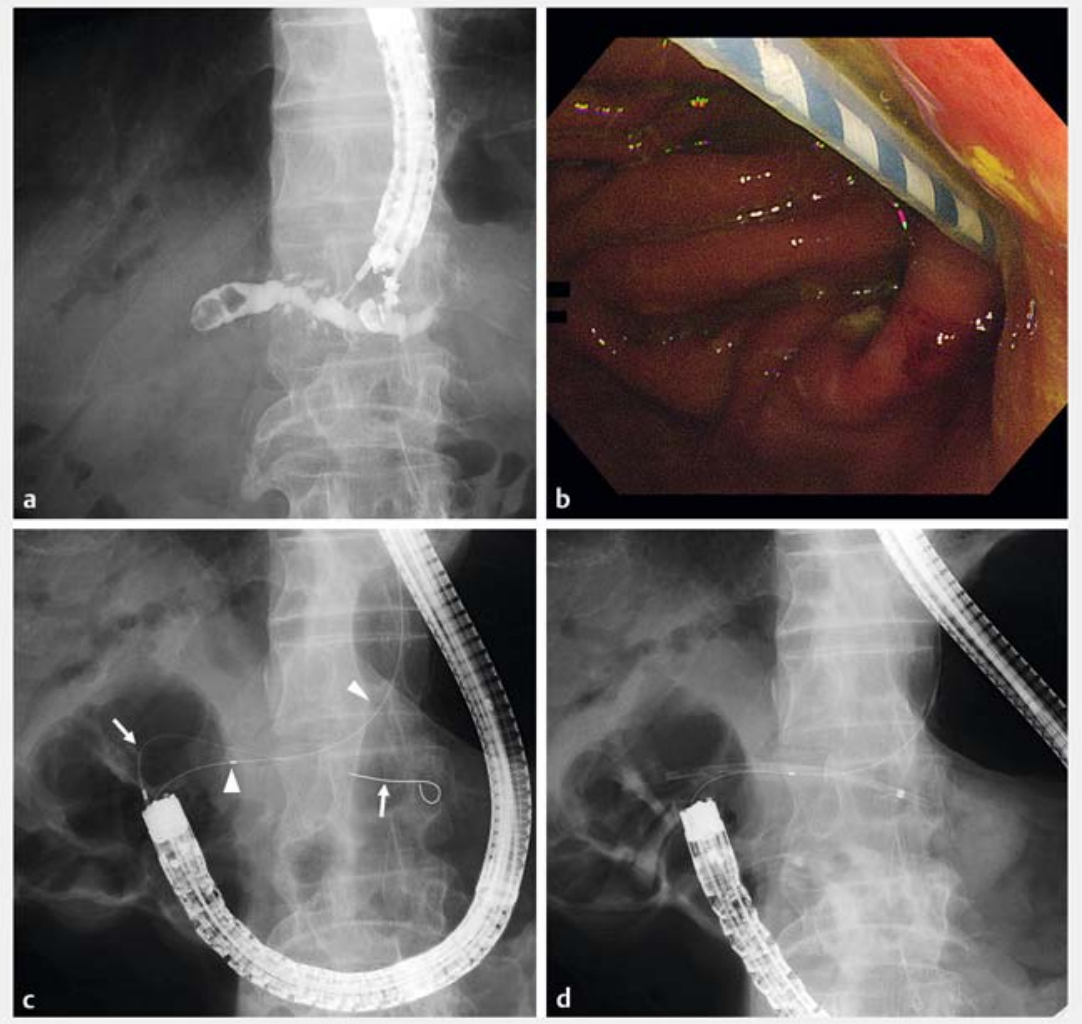

- Fig. 2 a Pancreatography showing the obstruction of the pancreatic duct with round defects caused by the pancreatic stones. $\mathbf{b}$ The catheter over the guidewire is placed through the gastro-pancreatic fistula. c A guidewire (arrows) is placed in the pancreatic duct after the EUS-placed guidewire had been held in the accessory channel (arrowheads). $\mathbf{d}$ A pancreatic stent is successfully placed across the pancreaticojejunal anastomosis.

cessory channel. The EUS-placed catheter and guidewire remained in the PD while another catheter and guidewire were inserted. This second guidewire accidentally dropped out of the PD; however, the EUS-placed guidewire was regripped as it was held in the accessory channel. The pancreaticojejunal anastomosis was dilated by the balloon catheter. Another guidewire was inserted, and a 7-Fr pancreatic stent was placed across the anastomosis ( $\vee$ Video 1 ). The patient was discharged 6 days later without any complications.

The EUS-guided hybrid rendezvous technique was effective when reattempting the procedure after the guidewire was dropped. It also maintained scope stability by keeping hold of the guidewire, allowing PD stenting to be accomplished.

Endoscopy_UCTN_Code_TTT_1AS_2AD

\section{Competing interests}

The authors declare that they have no conflict of interest. 


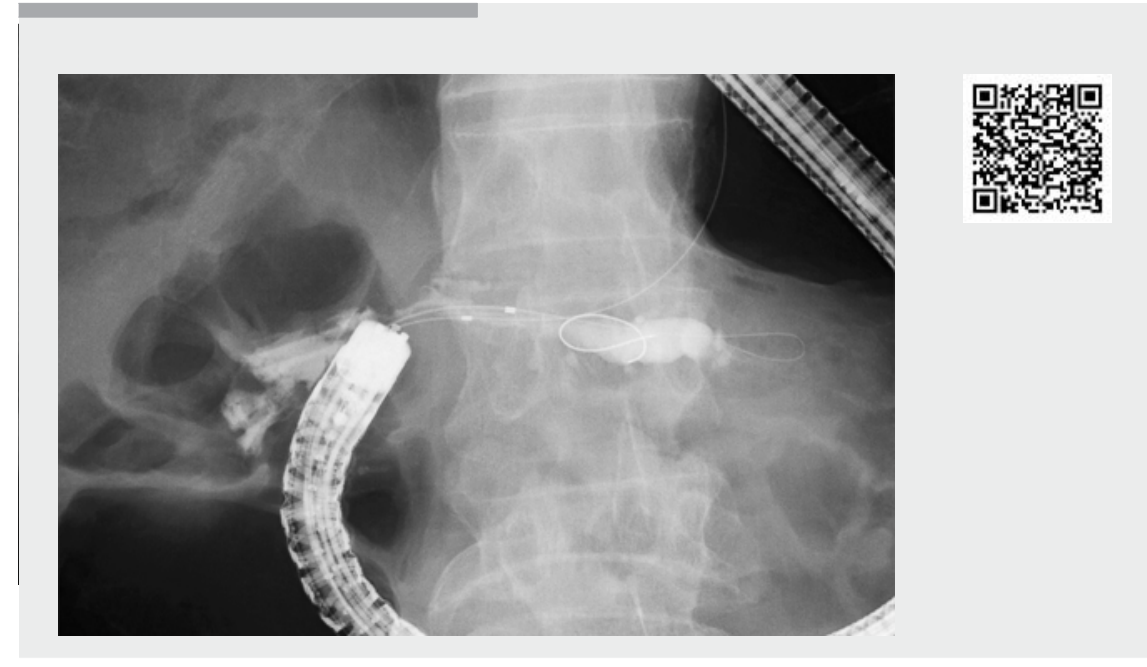

$\checkmark$ Video 1 A case in which the endoscopic ultrasonography-guided hybrid rendezvous technique was effective in achieving pancreatic stenting across the pancreaticojejunal anastomosis.

The authors

\section{Shinichi Hashimoto, Shiroh Tanoue, Yusuke} Fujino, Makoto Hinokuchi, Hiromichi Iwaya, Shiho Arima, Akio Ido

Department of Digestive and Lifestyle Diseases, Kagoshima University Graduate School of Medical and Dental Sciences, Kagoshima, Kagoshima, Japan

\section{Corresponding author}

\section{Shinichi Hashimoto, MD}

Department of Digestive and Lifestyle Diseases, Kagoshima University Graduate School of Medical and Dental Sciences, 8-35-1, Sakuragaoka, Kagoshima 890-8520, Japan

Fax: +81-99-264-3504

kumdsh@m.kufm.kagoshima-u.ac.jp

\section{Bibliography}

Endoscopy 2021; 53: E213-E214

DOI 10.1055/a-1244-9482

ISSN 0013-726X

published online 11.9 .2020

(c) 2020. Thieme. All rights reserved.

Georg Thieme Verlag KG, Rüdigerstraße 14,

70469 Stuttgart, Germany

\section{ENDOSCOPY E-VIDEOS \\ https://eref.thieme.de/e-videos}

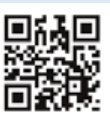

Endoscopy E-Videos is a free access online section, reporting on interesting cases and new

techniques in gastroenterological endoscopy. All papers include a high quality video and all contributions are freely accessible online.

This section has its own submission website at https://mc.manuscriptcentral.com/e-videos
[1] Nakai Y, Kogure H, Isayama $\mathrm{H}$ et al. Endoscopic ultrasound-guided pancreatic duct drainage. Saudi J Gastroenterol 2019; 25 : 210-217

[2] Itoi T, Kasuya K, Sofuni A et al. Endoscopic ultrasonography-guided pancreatic duct access: techniques and literature review of pancreatography, transmural drainage and rendezvous techniques. Dig Endosc 2013; 25: $241-252$

[3] Iwashita T, Uemura S, Yoshida K et al. EUSguided hybrid rendezvous technique as salvage for standard rendezvous with intrahepatic bile duct approach. PLoS One 2018; 13: e0202445 